This is the accepted version of the following article:

Muñoz J., Montes R., Bastos-Arrieta J., Guardingo M., Busqué F., Ruíz-Molina D., Palet C. García-Orellana J., Baeza M.. Carbon nanotube-based nanocomposite sensor tuned with a catechol as novel electrochemical recognition platform of uranyl ion in aqueous samples. Sensors and Actuators, B: Chemical, (2018). 273. : 1807 - . 10.1016/j.snb.2018.07.093,

which has been published in final form at https://dx.doi.org/10.1016/j.snb.2018.07.093 ( https://dx.doi.org/10.1016/j.snb.2018.07.093. This manuscript version is made available under the CC-BY-NC-ND 4.0 license http://creativecommons.org/licenses/by-nc-nd/4.0/ 


\section{Accepted Manuscript}

Title: Carbon nanotube-based nanocomposite sensor tuned with a catechol as novel electrochemical recognition platform of uranyl ion in aqueous samples

Authors: Jose Muñoz, Raquel Montes, Julio Bastos-Arrieta, Mireia Guardingo, Félix Busqué, Daniel Ruíz-Molina, Cristina Palet, Jordi García-Orellana, Mireia Baeza

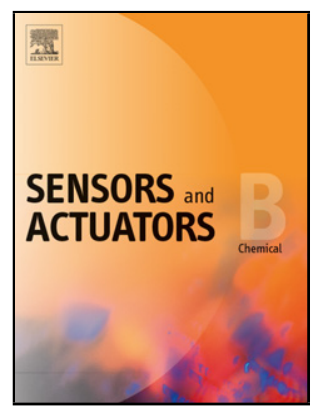

PII:

S0925-4005(18)31332-7

DOI: $\quad$ https://doi.org/10.1016/j.snb.2018.07.093

Reference: $\quad$ SNB 25062

To appear in: $\quad$ Sensors and Actuators B

Received date: $\quad 23-1-2018$

Revised date: $\quad$ 27-6-2018

Accepted date: $\quad$ 17-7-2018

Please cite this article as: Muñoz J, Montes R, Bastos-Arrieta J, Guardingo M, Busqué F, Ruíz-Molina D, Palet C, García-Orellana J, Baeza M, Carbon nanotube-based nanocomposite sensor tuned with a catechol as novel electrochemical recognition platform of uranyl ion in aqueous samples, Sensors and Actuators: B. Chemical (2018), https://doi.org/10.1016/j.snb.2018.07.093

This is a PDF file of an unedited manuscript that has been accepted for publication. As a service to our customers we are providing this early version of the manuscript. The manuscript will undergo copyediting, typesetting, and review of the resulting proof before it is published in its final form. Please note that during the production process errors may be discovered which could affect the content, and all legal disclaimers that apply to the journal pertain. 


\title{
Carbon nanotube-based nanocomposite sensor tuned with a catechol as novel electrochemical recognition platform of uranyl ion in aqueous samples
}

\author{
Jose Muñoz, ${ }^{\mathrm{a}}$ Raquel Montes, ${ }^{\mathrm{b}}$ Julio Bastos-Arrieta, ${ }^{\mathrm{c}, \mathrm{d}}$ Mireia Guardingo, ${ }^{\mathrm{e}}$ Félix Busqué, ${ }^{\mathrm{f}}$ Daniel \\ Ruíz-Molina, ${ }^{\mathrm{e}}$ Cristina Palet, ${ }^{\mathrm{f}}$ Jordi García-Orellana, ${ }^{\mathrm{g}, \mathrm{h}}$ and Mireia Baeza, ${ }^{\mathrm{f}, *}$ \\ a Molecular Nanoscience and Organic Materials Group, Institut de Ciencia de Materials de Barcelona (ICMAB-CSIC), Campus de \\ la UAB, 08193 Cerdanyola del Vallès (Bellaterra), Spain

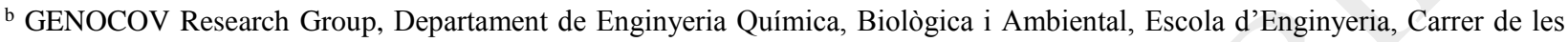 \\ Sitges, Universitat Autònoma de Barcelona, 08193 Cerdanyola del Vallès (Bellaterra), Spain \\ c Departament d'Enginyeria Química, Universitat Politècnica de Catalunya (UPC), Campus Diagonal Besòs, Edifici I (EEBE). \\ Avinguda Eduard Maristany, 10-14, 08019 Barcelona, Spain \\ ${ }^{\mathrm{d}}$ Barcelona Research Center for Multiscale Science and Engineering, 08019 Barcelona, Spain \\ e Institut Català de Nanociència i Nanotecnologia (ICN2), Edifici ICN2, Campus de la UAB, 08193 Cerdanyola del Vallès \\ (Bellaterra), Spain \\ ${ }^{\mathrm{f}}$ Departament de Química, Facultat de Ciències, Edifici C-Nord, Carrer del Til·lers, Universitat Autònoma de Barcelona, 08193 \\ Cerdanyola del Vallès (Bellaterra), Spain \\ ${ }^{g}$ Departament de Física, Facultat de Ciències, Edifici C-Nord, Carrer del Til·lers, Universitat Autònoma de Barcelona, 08193 \\ Cerdanyola del Vallès (Bellaterra), Spain \\ h Institut de Ciència i Tecnologia Ambientals (ICTA), Campus de la UAB, 08193 Cerdanyola del Vallès (Bellaterra), Spain \\ e-mail: mariadelmar.baeza@uab.cat
}

\section{Highlights}

- Synthesis and incorporation of Au-NPs carrying a thiolated catechol in nanocomposite carbon paste electrodes.

- Highly sensitive carbon nanotube-based amperometric sensor towards uranium in water.

- Excellent supramolecular recognition between uranyl ion and catechol, with a detection limit of $0.49 \mu \mathrm{g} \cdot \mathrm{L}^{-1}$.

- Feasibility of the present sensing platform in real mine samples. 


\begin{abstract}
This article reports a novel electrochemical recognition platform based on a nanocomposite carbon paste electrode containing carbon nanotubes modified with gold nanoparticles carrying a thiolated catechol for the fast amperometric determination of uranyl ion $\left(\mathrm{UO}_{2}{ }^{2+}\right)$ in water. Recognition of $\mathrm{UO}_{2}{ }^{2+}$ is accomplished by supramolecular chemistry due to the formation of an inclusion complex between catechol and $\mathrm{UO}_{2}{ }^{2+}$. The amperometric device operates at $-0.40 \mathrm{~V}$ vs. $\mathrm{Ag} / \mathrm{AgCl}$, where the reduction of $\mathrm{UO}_{2}{ }^{2+}$ takes place on the electrode surface, covering a linear range from 0.49 to $170 \mu \mathrm{g} \cdot \mathrm{L}^{-1} \mathrm{UO}_{2}{ }^{2+}$ in a $0.1 \mathrm{M}$ boric acid buffer solution at $\mathrm{pH}$ 5.3. The developed sensing system presents good response towards $\mathrm{UO}_{2}{ }^{2+}$ in aqueous environmental samples, with good selectivity over other browsed cations and can be easily reset by simple polishing. This platform has demonstrated to be a potential alternative regarding to the common standard bench-top analytical techniques for the development of in-field devices for in-situ monitoring.
\end{abstract}

Keywords: Uranyl; Supramolecular Chemistry; Carbon Paste Electrode; Gold Nanoparticles; Water Pollutants; Amperometry

\title{
1. Introduction
}

Uranium and its compounds are significant soil and/or water contaminants which are normally present in very low concentrations in various complex materials, such as alloys, plants, groundwater and industrial effluents [1]. Its presence in the environment is significantly associated to particulate and/or dissolved compounds as a contaminant in the different activities related to the nuclear cycle, such as mining, milling, enrichment, nuclear waste reprocessing or disposal. Although uranium could exist in different oxidation states, from (III) to (VI), uranium usually 
appears as a complex of the uranyl ion $\left(\mathrm{UO}_{2}{ }^{2+}\right)$, which is in its highest oxidation state (VI) [3]. Uranium, with its chemical and radiologic toxicity, can intake in human body especially from groundwater, vegetables, cereals and table salt [2]. For example, the U.S Environmental Protection Agency (EPA) has promulgated the Maximum Contamination Level (MCL) of $\mathrm{UO}_{2}{ }^{2+}$ for drinking water as low as $30 \mu \mathrm{g} \cdot \mathrm{L}^{-1}(130 \mathrm{nM})[4]$.

Standard $\mathrm{UO}_{2}{ }^{2+}$ analyses are mainly focused on bench-top laboratory instruments, including inductively coupled plasma-mass spectrometry (ICP-MS), radiometric techniques $(\alpha-$ and $\gamma$ - Spectrometry), neutron activation analysis and chromatography methods [5-9]. These techniques usually require some pre-concentration and extraction procedures, hindering their integration for in-field analysis. Some electrochemical platforms based on using conventional pure metal transducers have been investigated for uranyl ion determination [10-15]. However, such electrodes yielded detection limits higher than the promulgated by EPA [16]. Carbon-based pure electrodes, such as lead-coated glassy carbon electrodes [1], modified-graphite rods [17] and carboxylated graphene-coated electrodes [18] have demonstrated to improve significantly the detection limits over the aforementioned conventional electrodes above. Nonetheless, such electrochemical sensing platforms are mainly focused on deposited nanomaterials as recognition films on the top of the pure carbon electrode surfaces by drop-casting methodology [19], [20]. This approach often presents an inadequate analytical performance because of the low reproducibility derived from the frail electrode modification.

Nanocomposite carbon paste electrodes (NC-CPEs) allow a tailored electrode functionalization with a wide range of (bio)recognition elements thanks to the plastic nature of the composite [21], resulting in biocompatible electrodes easily reset by a simple polishing step. Further, NC-CPEs have demonstrated their feasibility to be easily integrated as amperometric detector in a microfluidic device for in field analysis [22]. The miniaturization of analyzers 
provides an easy automated measurement process for the electrochemical sensor and additional advantages such as low reagent and sample consumption, high portability, fast sample analysis, low production cost and robustness. Concretely, NC-CPEs based on CNTs as conducting filler (NC-CnPEs) confer remarkable electrical, thermal, mechanical and electrochemical properties to the final transducer for amperometric (bio)sensing purposes. Despite such features, it is known that some electroanalytical parameters, such as sensitivity, response time, background current, electrontransfer rate and detection limits are strongly influenced by the raw CNT nature, which in turn also affects the CNT/polymer composition ratio [23-25]. Recently, an electrochemical sensor array based on ion imprinted sol-gel modified graphite CPE has been reported, achieving high sensitivity and selectivity for $\mathrm{UO}_{2}^{2+}$, although, the preparation of such imprinted sol-gel films is quite tedious [26].

The use of (bio)recognition agents can pre-concentrate the analyte on the electrode surface, improving several analytical parameters such as sensitivity, (enantio)selectivity as well as detection limits [21], [27], [28]. Catechols are compounds that contain two neighboring hydroxyl groups in an aromatic ring [29]. This structure can be found in nature taking part in a plethora of processes, demonstrating excellent chelating properties towards different metal ions [30]. They can act as recognition agents, hosting effectively and selectively various inorganic guest molecules to produce three-dimensional structures with different inorganic compounds [31], including $\mathrm{UO}_{2}{ }^{2+}$ [32-34]. Tuning carbon nanoallotropes with gold nanoparticles (Au-NPs) makes possible the immobilization of those (bio)recognition elements containing thiolated groups. This approach has been widely exploited in electrochemical biosensing due to the resulting enhanced electron transfer between (bio)molecules and Au-NPs [35-37].

Accordingly, the goal of this work has been focused on the development of a highly selective, sensitive and renewable $\mathrm{NC}-\mathrm{CnPE}$ towards the determination of $\mathrm{UO}_{2}{ }^{2+}$ in aqueous media. 
The CNT-based electrochemical sensor is based on four sequential stages, as is described in Scheme 1: CNTs are (i) firstly tuned with Au-NPs via the Intermatrix Synthesis (IMS) technique, where a previous incorporation of $\mathrm{Cu}-\mathrm{NPs}$ as sacrificial nanotemplates on CNTs walls was necessary for galvanic replacement with $\mathrm{Au}^{3+}$ [38]; and (ii) then loaded with a synthesized thiolated catechol (cat-1) as recognition agent by covalently thiol-gold bond formation. (iii) The resulting hybrid-nanomaterial is dispersed within an insulating epoxy resin in an optimum composition ratio (10\% w/w in CNTs) in order to achieve a robust $\mathrm{NC}-\mathrm{CnPE}$ [24]; (iv) which was finally exploited as the highly sensitive amperometric recognition platform for $\mathrm{UO}_{2}{ }^{2+}$ sensing in water at part per billion $\left(\mu \mathrm{g} \cdot \mathrm{L}^{-1}\right)$ levels. Finally, the feasibility of this sensor towards $\mathrm{UO}_{2}{ }^{2+}$ was successfully demonstrated in environmental samples, showing an excellent sensitivity and efficient selectivity, where results are well in agreement with the ones obtained by the common bench-top spectroscopic techniques.

\section{Scheme 1}

\section{Materials and Methods}

\subsection{Chemicals and reagents}

Raw multiwalled CNTs (purity $>95 \%$, length 5-15 $\mu \mathrm{m}$, outer diameter 10-30 nm) were provided by SES Research (Houston, TX, USA). Epotek H77A and its corresponding hardener Epotek H77B were obtained from Epoxy Technology (Billerica, MA, USA) and were used as polymeric matrix. Au-NPs were synthesized using the $\mathrm{HAuCl}_{4}$ salt precursor $(>99.99 \%$ ), which was supplied by Sigma-Aldrich (St. Louis, MO, USA). Aqueous $\mathrm{UO}_{2}{ }^{2+}$ stock solution (980 ppm) was also purchased by Sigma-Aldrich. All solutions were prepared using deionized water 18.2 $\mathrm{M} \Omega \cdot \mathrm{cm}$ from a Milli-Q system (Millipore, Billerica, MA, USA). Boric acid (99\%) was provided 
by Panreac (Castellar del Vallès, Barcelona, Spain). All reagents were of the highest grade available and used without further purification. Four different real samples from Spanish mine wells rich in uranyl ion were provided by the Berkeley Energia in the framework of the Salamanca Uranium project (named as $\mathrm{S}_{1}, \mathrm{~S}_{2}$ and $\mathrm{S}_{3}$ ), and an additional intercomparison sample $\left(\mathrm{S}_{4}\right)$ from the Consejo de Seguridad Nuclear (National Security Council, CSN-2015).

\subsection{Synthesis of thiolated catechol recognition agent}

Thiolated catechol 1 (cat-1) was employed as recognition agent for sensing purposes and synthesized through a straightforward synthetic route outlined in Scheme 2. Briefly, a thiol-ene reaction of starting commercial 4-allyl-2-metoxiprhenol with thioacetic acid, using azoisobutyronitryle (AIBN) as free radical initiator, gave the corresponding 4-(3'thioacetyl)propyl-1-hydroxy-2-metoxybenzene (2) adduct in $87 \%$ yield. Afterwards, it was transformed in the garget thiolated cat-1 by sequential demethylation with $\mathrm{BBr}_{3}$ to obtain catechol intermediate 4-(3'-thioacetyl)propylcatechol (3) in $90 \%$ yield, and final basic hydrolysis of the thioacetate moiety ( $89 \%$ yield). Whole synthesis information and characterization is available in Supporting Information.

\section{Scheme 2}

\subsection{Synthesis of carbon-based hybrid-nanomaterials}

Synthesis of functionalized-CNTs with Au-NPs (Au-NP@CNTs) was carried out by the IMS environmentally friendly technique, following the same methodology previously developed in our research group [38]. Briefly, CNTs were previously activated with a $2.5 \mathrm{M} \mathrm{HNO}_{3}$ solution, resulting in the CNTs-COOH. CNTs-COOH were firstly loaded with a $0.01 \mathrm{M} \mathrm{Cu}^{2+}$ aqueous 
solution followed by reduction with $0.1 \mathrm{M} \mathrm{NaBH}_{4}$ under magnetic stirring at ambient condition, resulting in the $\mathrm{Cu}-\mathrm{NP} @ \mathrm{CNTs}$. Afterwards, the $\mathrm{Cu}-\mathrm{NP} @ \mathrm{CNT}$ s were immersed in a $0.01 \mathrm{M}$ $\mathrm{HAuCl}_{4}$ aqueous solution for a stoichiometry galvanic replacement reaction between $\mathrm{Au}^{3+} \mathrm{and} \mathrm{Cu}^{0}$. Once the Au-NP@CNTs hybrid-nanomaterial was obtained, the resultant product was dispersed in $50 \mathrm{~mL}$ of Milli-Q water and set to stir at room temperature for $30 \mathrm{~min}$. Following this, $50 \mathrm{~mL}$ of an aqueous (9:1 water/ethanol, v/v) $2.0 \mathrm{mM}$ suspension of cat-1 was added. The solution was left to stir overnight. Finally, the product was centrifuged for $10 \mathrm{~min}$ and washed several times with Milli-Q water and ethanol in order to remove the unbound cat-1 material. The resultant cat-1/AuNP@CNTs hybrid-nanomaterial was dried overnight at $80^{\circ} \mathrm{C}$.

\subsection{Characterization of hybrid-nanomaterials}

Physical characterization of raw CNTs, Au-NP@CNTs and cat-1/Au-NP@CNTs were obtained from High-Resolution Transmission Electron Microscopy (HR-TEM), using a JEM-2011 unit with $200 \mathrm{kV}$ of acceleration voltage coupled to an Energy Dispersive X-Ray Spectroscopy (EDS). Thermogravimetric Analysis (TGA) technique was used to quantify both the total metal content and the recognition agent content in the hybrid-nanomaterials. The experiments were carried out using a Netzsch instrument; model STA 449 F1 Jupiter®. Approximately 20 mg of sample was heated to $1000{ }^{\circ} \mathrm{C}$ at $10{ }^{\circ} \mathrm{C} \cdot \mathrm{min}^{-1}$, using air flow. The mass of the sample was continuously measured as a function of temperature and the rate of weight loss (d.t.g.) was automatically recorded. The number of the cat-1 per Au-NPs has been measured following the supporting information from Tom's work [39].

\subsection{Preparation of nanocomposite electrodes}


Handmade working $\mathrm{NC}-\mathrm{CnPEs}$ were prepared using a cylindrical polyvinyl chloride (PVC) tube body (6 mm of internal diameter and $20 \mathrm{~mm}$ of length) and a small copper disk (6 mm of diameter and $1 \mathrm{~mm}$ of thickness) soldered at the end of an electrical connector ( $2 \mathrm{~mm}$ of diameter). The working $\mathrm{NC}-\mathrm{CnPE}$ was prepared by mixing manually a previously optimized composition [24] of cat-1/Au-NP@CNTs and epoxy resin (10:90,w/w) for $1 \mathrm{~h}$. The mixture was then incorporated in the hollow end of a PVC tube to form the body of the electrode and allowed to harden during $24 \mathrm{~h}$ at $80^{\circ} \mathrm{C}$. Finally, electrode surfaces were polished with different sandpapers of decreasing grain size (800 and 1200) and alumina paper (polishing strips 948201, Orion) in order to obtain a reproducible electrochemical surface. The resultant geometric area for the final electrodes was $28 \mathrm{~mm}^{2}$. For blank experiments, bare NC-CnPEs were fabricated, which are based on a dispersion of raw CNTs (without any further functionalization) within the epoxy resin in a 10:90 w/w ratio, respectively.

\subsection{Electrochemical performance}

Electrochemical measurements were carried out by means of cyclic voltammetry (CV) and electrochemical impedance spectroscopy (EIS), using a computer controlled Autolab PGSTAT12 potentiostat/galvanostat (Eco Chemie, Utrech, The Netherlands) in a three-electrode configuration cell. A single junction reference electrode $\mathrm{Ag} / \mathrm{AgCl}$ Orion 900200 (Thermo Electron Corporation, Beverly, MA, USA) and a platinum-based electrode 52-671 (Crison Instruments, Alella, Barcelona, Spain) were used as reference and auxiliary electrodes, respectively. The developed NC-CnPEs were employed as working electrodes. All experiments were performed at room temperature. In case of EIS measurements, the reference electrode used was an $\mathrm{AgCl}$ covered silver wire. 
Characterization involving $\mathrm{CV}$ were made in the aforementioned three-electrode configuration cell filled with $10 \mathrm{~mL}$ of $0.1 \mathrm{M}$ boric acid buffer solution ( $\mathrm{pH} 5.3$ ) as supporting electrolyte for $\mathrm{UO}_{2}{ }^{2+}$ determination since it has been found to be the optimum conditions for supramolecular chemistry [17], [40]. Voltammetric experiments were studied at different scan rates (from 5 to $100 \mathrm{mV} \cdot \mathrm{s}^{-1}$ ). $\mathrm{CV}$ uranyl ion determination was recorded by adding directly different aliquots of $\mathrm{UO}_{2}{ }^{2+}$ into the electrochemical cell, where a 10-minute incubation step took place under stirring conditions in order to promote the supramolecular complex formation between the recognition agent and the analyte.

EIS characterization was carried out in order to study the electrochemical performance of the different nanocomposite-based electrodes. The impedance spectra were recorded in the frequency range $0.1 \mathrm{~Hz}$ to $100 \mathrm{kHz}$ (signal amplitude to perturb the system was $10 \mathrm{mV}$ ). A $10 \mathrm{mM}$ $\left[\mathrm{Fe}(\mathrm{CN})_{6}\right]^{3-/ 4-}$ solution containing $0.1 \mathrm{M} \mathrm{KCl}$ was employed as the electrolyte, since $\left[\mathrm{Fe}(\mathrm{CN})_{6}\right]^{3-/ 4-}$ is a commonly used redox couple to investigate the electrochemical performances of modified electrode surfaces.

Electroanalytical measurements were carried by means of hydrodynamic amperometry using an amperimeter LC-4C (Bioanalytical Systems, Inc., West Lafayette, IN, USA). The experiments were performed using the aforementioned three-electrode configuration cell under constant stirring conditions at $-0.40 \mathrm{~V} v$ s. $\mathrm{Ag} / \mathrm{AgCl}$ fixed potential at atmospheric conditions. The electrochemical-cell was previously filled with $10 \mathrm{~mL}$ of $0.1 \mathrm{M}$ boric acid at $\mathrm{pH} 5.3$ as a supporting electrolyte for blank current measurement; then consecutive volume additions of the standard solution were added (see Experimental Procedure on Supplementary Material).

Regarding to statistics studies, each measurement was carried out per triplicate to determine the repeatability of the measurements. After each calibrate, the electrode surface was reset by a simple polishing step. The short- and long-term stability were investigated using a same sensor. 
For the short-term study, seven consecutive measurements were made for a same uranyl ion concentration $(n=7)$. For the long-term study, calibration plots were compiled for a 30-day period. The repeatability of the method was studied per triplicate carrying out different calibrates after refreshing the electrode surface by a simple polishing step. The fabrication reproducibility was investigated by preparing three different sensors $(n=3)$, also collecting three different measurements for each sensor $(n=9)$. Thus, both detection limit (LOD) and quantification limit (LOQ) are presented with their respectively $95 \%$ confidence interval [41].

\subsection{Uranium determination in real samples}

Three analytical methods were used for the analysis of real samples: two bench-top spectroscopic techniques, such as $\alpha$-Spectrometry and ICP-MS, and hydrodynamic amperometry. Alpha emission measurements of total uranium amount were carried out with a Canberra $\alpha$-analyst system using Passivated Implanted Planar Silicon (PIPS) detectors. The radiochemical separation of $\mathrm{U}(\mathrm{U}-238, \mathrm{U}-235$ and $\mathrm{U}-234)$ from the environmental samples was previously carried out by extraction chromatography, using UTEVA resins and electrodeposition of $\alpha$-emitters onto $2.2 \mathrm{~cm}$ diameter silver discs, using ${ }^{232} \mathrm{U}$ as internal yield tracer [42]. ICP-MS analysis of uranyl ion was carried out using to two different equipments: ICP-MS-1 (XSERIES 2 ICP-MS, Thermo Scientific, USA) and ICP-MS-2 (Model 7500ce, Agilent Technologies, Inc., USA).

Electroanalytical measurements of uranyl ion were carried out by hydrodynamic amperometry following the methodology previously described on Section 2.6.

\section{Results and Discussion}

\subsection{Physical characterization of hybrid-nanomaterials}


HR-TEM was employed to monitor the CNT-based nanomaterials at different functionalization stages. HR-TEM images from Figure 1 (A to B) clearly show a homogeneous functionalization of the CNTs with Au-NPs. The average particle size was $3.2 \pm 0.2 \mathrm{~nm}$ (see Figure S1). The resulting Au-NPs@CNTs hybrid-nanomaterial was used as a template for carrying the thiolated recognition element (cat-1), being the strength of the gold-thiol interactions the basis to obtain a robust cat-1/Au-NP@CNTs hybrid-nanomaterial (see Figure 1C) [41]. The EDS spectrum from Figure 1D confirmed both the presence $\mathrm{Au}-\mathrm{NPs}$ as well as the $\mathrm{S}$ peak provided by the thiolated cat-1. The $\mathrm{Cu}$ peak observed is due to the TEM grid.

TGA experiments were used to quantify the wt \% of Au-NPs and cat-1 on the CNTs walls. TGA analysis also demonstrated the functionalization of the raw CNT material at the different functionalization steps, with an amount of $18.9 \mathrm{wt} \%$ in Au-NPs and $24.7 \mathrm{wt} \%$ in cat-1 (see Figure S2). The proportion of number of recognition agent per Au-NPs with an average diameter of 3.2 $\pm 0.2 \mathrm{~nm}$ is $\mathrm{n} \approx 3000$. This high amount of molecules ensures an excellent supramolecular recognition platform with improved ability for $\mathrm{UO}_{2}{ }^{2+}$ detection at low concentrations [37].

\section{Figure 1}

\subsection{Electrochemical characterization of the recognition system}

The electrochemical behavior of the bare electrode (CNTs/epoxy) and functionalized NCCnPE (cat-1/Au-NP@CNTs/epoxy) was evaluated via EIS and CV.

EIS technique was used to characterize the electrochemical performance of the different nanocomposite-based electrodes containing $i$ ) CNTs activated with carboxylic groups (bare electrode); ii) Au-NP@CNTs and iii) cat-1/Au-NP@CNTs, since it is a very sensitive tool for surface characterization (Figure 2A). Randles circuit was used for fitting the impedance data (inset) 
[43], where: a) $R_{\Omega}$ is the solution resistance, which is dependent on the ionic concentration, the type of ions and also de electrode area, b) $\mathrm{R}_{\mathrm{CT}}$ is the charge-transfer resistance, which depends on the dielectric and insulating properties of the electrode/electrolyte interface, and it is inversely proportional to the electron-transfer rate, c) $\mathrm{C}_{\mathrm{dl}}$ is the double-layer capacitance, which is directly related to the charging and background current and d) $Z_{W}$ is the Warburgh impedance, which arises from mass-transfer limitations and can be used to measure effective diffusion coefficients. Chargetransfer resistance $\left(\mathrm{R}_{\mathrm{CT}}\right)$ was determined by the semicircle diameter $\left(\mathrm{Z}_{\text {real }}\right)$ from Nyquist plots. After modifying the bare $\mathrm{NC}-\mathrm{CPE}$ with $\mathrm{Au}-\mathrm{NPs}$, the $\mathrm{R}_{\mathrm{CT}}$ value clearly decreases from $573.7 \Omega$ to $220.0 \Omega$. As the conductor material load increases, the probability of having more electroactive sites on the electrode surface also increases, as well as the electrode kinetics. Finally, a significant $\mathrm{R}_{\mathrm{CT}}$ value increase from $220.0 \Omega$ to $488.1 \Omega$ was achieved after the recognition agent (cat-1) incorporation because of the insulating nature of the catechol. Accordingly, it has been impedimetrically demonstrated a successful functionalization of carbon nanotubes with both $\mathrm{Au}-$ NPs and recognition element.

Meanwhile the $\mathrm{CV}$ from the bare electrode (Figure 2B, curve a) does not present any redox peak, CV from the functionalized electrode (Figure 2B, curve b) reveals two pairs of well-defined peaks. The first pair of redox peaks $\left(\mathrm{E}_{\mathrm{a} 1} / \mathrm{E}_{\mathrm{cl}}\right)$ is attributed to the redox reaction of $\mathrm{Au}-\mathrm{NPs}$, which was found around $+0.55 \mathrm{~V} v$ s. $\mathrm{Ag} / \mathrm{AgCl}\left(\mathrm{E}_{\mathrm{a} 1}\right)$ and $+0.40 \mathrm{~V} v$ s. $\mathrm{Ag} / \mathrm{AgCl}\left(\mathrm{E}_{\mathrm{cl}}\right)$ [44]. According to the proposed mechanism found in literature, the second pair of redox peaks $\left(\mathrm{E}_{\mathrm{a} 2} / \mathrm{E}_{\mathrm{c} 2}\right)$ observed around $+1.20 \mathrm{~V} v s . \mathrm{Ag} / \mathrm{AgCl}\left(\mathrm{E}_{\mathrm{a} 2}\right)$ and $+0.75 \mathrm{~V} v s . \mathrm{Ag} / \mathrm{AgCl}\left(\mathrm{E}_{\mathrm{c} 2}\right)$ correspond to the catechol redox couple. The anodic peak $\mathrm{E}_{\mathrm{a} 2}$ pertains to the oxidation of cat-1 to the [cat-1 $]^{\bullet+}$ and the cathodic peak $\mathrm{E}_{\mathrm{c} 2}$ is its counterpart [45]. Thus, these two-pair of redox peaks evidences again the presence of both $\mathrm{Au}-\mathrm{NPs}$ and recognition agent on the nanocomposite electrode surface. It is important to point out that all those pair of redox peaks did not change when increasing the number of CV cycles, 
indicating that there is no evidence of nanoparticles or catechol desorption. After consecutive additions of $0.98 \mu \mathrm{g} \cdot \mathrm{L}^{-1} \mathrm{UO}_{2}{ }^{2+}$ solution (see Figure $2 \mathrm{~B}$, curves $\mathrm{c}$ and $\mathrm{d}$ ), a third cathodic peak $\left(\mathrm{E}_{\mathrm{c} 3}\right.$ ) at $-0.40 \mathrm{~V} v s . \mathrm{Ag} / \mathrm{AgCl}$ was observed, which must correspond to the reduction of $\mathrm{UO}_{2}{ }^{2+}$ to $\mathrm{UO}_{2}{ }^{+}$, obviously increasing its intensity current with increasing uranyl ion concentration.

\section{Figure 2}

\subsection{Electroanalytical performance at the recognition system}

The electroanalytical evaluation of the developed sensing platform has been performed by hydrodynamic amperometry at fixed potential as described on Section 2.6.

Figure 3 shows the calibration curve at the developed sensor in a $10 \mathrm{~mL} 0.1 \mathrm{M}$ boric acid solution ( $\mathrm{pH} 5.3$ ) with subsequent additions of $0.98 \mu \mathrm{g} \cdot \mathrm{L}^{-1} \mathrm{UO}_{2}{ }^{2+}$ aliquots. The dependence of the current $\left(I_{p}\right)$ of $\mathrm{UO}_{2}{ }^{2+}$ on its concentration was linearly related to the $\left[\mathrm{UO}_{2}{ }^{2+}\right]$ in the range of 0.49 to $170 \mu \mathrm{g} \cdot \mathrm{L}^{-1}$ (see Table S1). The lineal regression equation was $I_{p}(\mu \mathrm{A})=0.001 \pm 0.002-0.0019 \pm$ $0.0005\left[\mathrm{UO}_{2}{ }^{2+}\right]\left(\mu \mathrm{g} \cdot \mathrm{L}^{-1}\right)$, with the correlation coefficient $\left(r^{2}\right)$ of $0.999(n=15)$. The LOD and LOQ were found to be $0.49 \pm 0.01 \mu \mathrm{g} \cdot \mathrm{L}^{-1}$ and $0.98 \pm 0.01 \mu \mathrm{g} \cdot \mathrm{L}^{-1}$, respectively. Both LOD and/or lineal range of the novel recognition platform were improved regarding most of previously developed carbon-based electrochemical electrodes (modified or not) reported in literature [46-49]. This analytical enhancement may be attributed to a synergistic effect between the 1D nanofiller material and the recognition element, promoting electron transfer in the reduction of $\mathrm{UO}_{2}{ }^{2+}$ on the electrode surface after recognition step. In addition, as added value, it is the first time from our knowledge that a renewable modified electrochemical sensor containing a recognition agent is developed for this aim. Additionally, it is important to point out that a blank study was carried out using the bare $\mathrm{NC}-\mathrm{CnPE}$, which no sensitivity towards $\mathrm{UO}_{2}{ }^{2+}$ was observed in the range of concentrations used for electroanalytical experiments (from 0.5 to $170 \mu \mathrm{g} \cdot \mathrm{L}^{-1}$ ). These results verified the prominent 
role of the recognition element to achieve a highly sensitive sensing platform.

\section{Figure 3}

\subsection{Stability, repeatability and reproducibility}

The stability, reproducibility and repeatability of the developed devices were evaluated by hydrodynamic amperometry (see Table S2).

The short-term stability of the sensors was also investigated by repeating the determination of $10 \mu \mathrm{g} \cdot \mathrm{L}^{-1} \mathrm{UO}_{2}{ }^{2+}$ aliquots seven times at the same sensor. The seven measurements achieved a good repeatability with the relative standard deviation (RSD) of $3.9 \%$. Afterwards, multiple calibration experiments were performed with the same nanocomposite sensor within a 30-day period in order to make an estimation of the loss of sensitivity to both short and long time. The mean value of the calibration plots carried out the first working day was used as the control sensitivity value. During this period, the sensor was exposed to air without renewing their surface. A simple approach was implemented to remove the formed complex on the electrode surface in order to reactivate the electrode surface without needing to renew its surface by polishing. This pretreatment consisted of applying, before each measurement or calibration, several cycles between $+1.23 \mathrm{~V}$ and $-0.83 \mathrm{~V}$ vs. $\mathrm{Ag} / \mathrm{AgCl}$ during $30 \mathrm{~s}$ each cycle. After 30 days, the current response of the device was approximately $97.8 \%$ of its original counterpart. This fact can be mainly attributed to the chemical stability of the recognition agent, which is trapped by the polymeric matrix. Results demonstrated that the simple procedure explained above enables the sensor to be used for at least 30 days without having significant differences in sensitivity, reflecting the high mechanical stability and reusability nature of the developed $\mathrm{NC}-\mathrm{CnPE}$.

On other hand, a refreshed electrode surface was obtained by simple polishing process in order to estimate the repeatability of the process between three different calibrates, with a RSD of 
$2 \%$. Such results demonstrate a superb repeatable system. Finally, the fabrication reproducibility by preparing three different nanocomposite sensors was investigated. The amperometric response of $10 \mu \mathrm{g} \cdot \mathrm{L}^{-1} \mathrm{UO}_{2}{ }^{2+}$ was evaluated per triplicate $(n=3)$. The RSD of $6.3 \%$ indicates that the preparation method is highly reproducible.

\subsection{Interference study}

The selectivity of this sensing method for uranyl ion was amperometrically evaluated (see Figure 4). Anti-interference property is also an important factor for sensors. Accordingly, effects of co-existing ions such as $\mathrm{Al}^{3+}, \mathrm{Cd}^{2+}, \mathrm{Co}^{2+}, \mathrm{Fe}^{2+}, \mathrm{Fe}^{3+}, \mathrm{Pb}^{2+}$ and $\mathrm{Ru}^{+}$, which are great significance in environmental matrices, were examined at the recognition system. The hydrodynamic amperometric response of the developed sensor was monitored in a $10 \mathrm{~mL} 0.1 \mathrm{M}$ boric acid solution at $\mathrm{pH}$ 5.3. The interference experiments were carried out per triplicate $(n=3)$ by analyzing the interfering species at $10 \mu \mathrm{g} \cdot \mathrm{L}^{-1}$ concentration using the present recognition platform.

\section{Figure 4}

As it is observed in Figure 4 (dashed line), only $\mathrm{Fe}^{2+}, \mathrm{Fe}^{3+}$ and $\mathrm{Pb}^{2+}$ cations showed significant response ( $>5 \%$ compared to the $\mathrm{UO}_{2}{ }^{2+}$ response) at the recognition system when they are present separately, although still over twice lower than for $\mathrm{UO}_{2}{ }^{2+}$. These results reflect the superior complexing behavior of the recognition sensing platform towards uranyl ions over other matrix components which might be present in similar concentrations, fact that motivated us to explore its use in various real samples. Statistics values from the analytical data are summarized in Table S3.

\subsection{Real samples}


After being proved the amperometric performance of the developed $\mathrm{NC}-\mathrm{CnPE}$ towards the determination of $\mathrm{UO}_{2}{ }^{2+}$ in a buffer solution, experiments were then conducted in real environmental samples. All the measurements were obtained per triplicate $(n=3)$. Four different samples $\left(\mathrm{S}_{1}, \mathrm{~S}_{2}\right.$, $\mathrm{S}_{3}$ and $\mathrm{S}_{4}$ ) providing from Spanish mine wells rich in uranyl ion were analyzed using the developed sensing platform. Table 1 summarizes the results of the uranyl concentration using the developed sensor, which were compared with those obtained by the standard analytical techniques, such as $\alpha$ - Spectrometry and two different ICP-MS equipment. As it can be observed, the results obtained by the present recognition system agrees well with those ones obtained by the reference spectroscopic techniques, despite lead and iron ions are interferents (see Figure 4). Thus, it has been clearly certified the applicability of this amperometric sensing platform for $\mathrm{UO}_{2}{ }^{2+}$ determination in environmental samples. Finally, it is important to highlight a significant variability of the analytical results depending on the spectroscopic technique used, especially for the $S_{2}$ sample, even when the spectroscopic technique is the same, but equipment used was different (note values obtained by ICP-MS (1) and (2)). However, no significant differences were observed when two different series of sensors were employed, with a $95 \%$ confident level in paired $\mathrm{t}$-test: $\mathrm{t}_{\mathrm{cal}}=1.0$ $<\mathrm{t}_{\mathrm{tab}}=4.3$, exhibiting excellent repeatability and reproducibility.

\section{Conclusions}

A thiolated catechol 1 has been $i$ ) synthesized, $i i$ ) attached property upon functionalizedCNTs containing $\mathrm{Au}-\mathrm{NPs}$ and iii) dispersed in an insulating epoxy resin in an optimum composition ratio for $i v$ ) the development of a $\mathrm{NC}-\mathrm{CnPE}$, which was used as sensitive electrochemical recognition platform towards the determination of $\mathrm{UO}_{2}{ }^{2+}$ in water. The electrochemical principle of the developed recognition system is based on the excellent 
supramolecular interactions between uranyl ion and catechol, favouring the redox reaction on the electrode surface. A wide linear response range from 0.49 to $170 \mu \mathrm{g} \cdot \mathrm{L}^{-1}$ (2.1 to $714 \mathrm{nM}$ ) was obtained, achieving the EPA MCL for drinking water $\left(30 \mu \mathrm{g} \cdot \mathrm{L}^{-1}\right.$ or $\left.130 \mathrm{nM}\right)$.

It is worthy to note that in spite of the recognition element showed considerable affinity towards some common metal cations, such as iron and lead, the feasibility of the present amperometric recognition system was verified in different environmental samples, obtaining promising results in comparison with other common spectroscopic methods for $\mathrm{UO}_{2}{ }^{2+}$ determination (i.e., $\alpha$-Spectrometry and ICP-MS methods). Such results suggest that the recognition platform is much more selective towards the uranyl ion even when different potential interfering ions coexist in the same matrix.

Besides a few different carbon-based electrochemical sensors can be found in the literature for uranyl ion determination with linear response ranges very similar (between 0.27 and $67.5 \mu \mathrm{g} \cdot \mathrm{L}^{-}$ ${ }^{1}$ ), none similar to this particular engineering nanocomposite-based recognition system has been exploited. The main advantage of the present sensor is the adequate integration of the recognition element throughout a polymeric matrix, resulting in a robust $\mathrm{NC}-\mathrm{CnPE}$ with a renewable surface by a simple polishing step, maximizing the lifetime of the sensor. This fact guarantees that a reproducible electrode surface is obtained and the properties of the recognition system are maintained, being possible to exploit these advantages towards the development of an inexpensive, fast, renewable and transportable device for the in-situ detection of $\mathrm{UO}_{2}{ }^{2+}$. Accordingly, the present nanocomposite-based recognition system provides the basis for improved and sustainable uranyl ion determination in water, and offers the opportunity for affordable sensors which can be comfortably integrated as a detector in an automated microfluidic analyzer for being applied at point-of-use, which is the final aim of our ongoing research. Such advances open up a wide range 
of applications in interesting environmental, geochemical and clinical investigations for continuous

or on-demand water analysis to give real-time indication of uranium concentration.

\section{Acknowledgments}

This work was supported by the Spanish project CTQ2012-36165 and CTQ2013-41161-R. Authors

also want to thank the support of the Generalitat de Catalunya to GSB (2014-SGR-837) and MERS

(2014-SGR-1356). Real samples from mine wells rich in uranyl ion were kindly supplied by Berkeley Energia and Consejo de Seguridad Nuclear (National Security Council, CSN-2015). Dr. J. Muñoz gratefully acknowledges the "Juan de la Cierva" programme.

\section{References}

[1] S. Betelu, C. Vautrin-UI, J. Ly, A. Chaussé, Screen-printed electrografted electrode for trace uranium analysis, Talanta, 80(2009) 372-6.

[2] S.C. Sheppard, M.I. Sheppard, M.-O. Gallerand, B. Sanipelli, Derivation of ecotoxicity thresholds for uranium, Journal of Environmental Radioactivity, 79(2005) 55-83.

[3] D. Brugge, J.L. deLemos, B. Oldmixon, Exposure pathways and health effects associated with chemical and radiological toxicity of natural uranium: a review, Reviews on environmental health, 20(2005) 177-94.

[4] U. Epa, EPA Integrated Risk Information System (IRIS) electronic database, US Environmental Protection Agency, Washington, DC, (1996).

[5] M. Rožmarić, A.G. Ivšić, Ž. Grahek, Determination of uranium and thorium in complex samples using chromatographic separation, ICP-MS and spectrophotometric detection, Talanta, 80(2009) 352-62.

[6] I. Pashalidis, H. Tsertos, Radiometric determination of uranium in natural waters after enrichment and separation by cationexchange and liquid-liquid extraction, Journal of radioanalytical and nuclear chemistry, 260(2004) 439-42.

[7] A. Khorfan, A. Wahoud, W. Rafool, A quick method to determine uranium concentration by gamma spectroscopy: Its application for extraction of uranium from wet phosphoric acid, Journal of Radioanalytical and Nuclear Chemistry, 257(2003) 313-6.

[8] A. El-Taher, INAA and DNAA for uranium determination in geological samples from Egypt, Applied Radiation and Isotopes, 68(2010) 1189-92.

[9] M. Lehritani, J. Mantero, N. Casacuberta, P. Masqué, R. García-Tenorio, Comparison of two sequential separation methods for $U$ and Th determination in environmental samples by alpha-particle spectrometry, Radiochimica Acta International journal for chemical aspects of nuclear science and technology, 100(2012) 431-8.

[10] S. Sander, W. Wagner, G. Henze, Possibilities for the automated determination of trace concentrations of uranium in water samples by adsorptive stripping voltammetry, Analytica Chimica Acta, 349(1997) 93-9.

[11] R. Ziółkowski, Ł. Górski, S. Oszwałdowski, E. Malinowska, Electrochemical uranyl biosensor with DNA oligonucleotides as receptor layer, Analytical and bioanalytical chemistry, 402(2012) 2259-66.

[12] R. Banerjee, Y. Katsenovich, L. Lagos, M. Senn, M. Naja, V. Balsamo, et al., Functional magnetic nanoshells integrated nanosensor for trace analysis of environmental uranium contamination, Electrochimica Acta, 55(2010) 7897-902.

[13] A. Becker, H. Tobias, Z.e. Porat, D. Mandler, Detection of uranium(VI) in aqueous solution by a calix[6]arene modified electrode, Journal of Electroanalytical Chemistry, 621(2008) 214-21.

[14] R.K. Shervedani, S.A. Mozaffari, Impedimetric sensing of uranyl ion based on phosphate functionalized cysteamine selfassembled monolayers, Analytica Chimica Acta, 562(2006) 223-8. 
[15] M. Lee, Y. Hur, J. Kim, H. Chop, K. Koh, Uranyl ion sensing by a self-assembled calix[6]arene monolayer, Molecular Crystals and Liquid Crystals Science and Technology Section A: Molecular Crystals and Liquid Crystals, 377(2002) 237-40.

[16] A. Bleise, P.R. Danesi, W. Burkart, Properties, use and health effects of depleted uranium (DU): a general overview, Journal of environmental radioactivity, 64(2003) 93-112.

[17] P.A. Dimovasilis, M.I. Prodromidis, An electrochemical sensor for trace uranium determination based on 6-O-palmitoyl-Iascorbic acid-modified graphite electrodes, Sensors and Actuators B: Chemical, 156(2011) 689-94.

[18] R. Ziółkowski, Ł. Górski, E. Malinowska, Carboxylated graphene as a sensing material for electrochemical uranyl ion detection, Sensors and Actuators B: Chemical, 238(2017) 540-7.

[19] F. Chávez, G. Pérez-Sánchez, O. Goiz, P. Zaca-Morán, R. Peña-Sierra, A. Morales-Acevedo, et al., Sensing performance of palladium-functionalized WO 3 nanowires by a drop-casting method, Applied Surface Science, 275(2013) 28-35.

[20] F. Della Pelle, L. Vázquez, M. Del Carlo, M. Sergi, D. Compagnone, A. Escarpa, Press-Printed Conductive Carbon Black Nanoparticle Films for Molecular Detection at the Microscale, Chemistry-A European Journal, 22(2016) 12761-6.

[21] J. Muñoz, M. Baeza, Customized Bio-Functionalization of Nanocomposite Carbon Paste Electrodes for Electrochemical Sensing: A Mini Review, Electroanalysis, 29(2017),1660-1669.

[22] R. Montes, F. Céspedes, M. Baeza, Determination of pesticides using a low-temperature co-fired ceramic microfluidic platform. Instrumentation Science \& Technology, 46: 1 (2018), 76-92.

[23] J. Muñoz, F. Cespedes, M. Baeza, Effect of carbon nanotubes purification on electroanalytical response of near-percolation amperometric nanocomposite sensors, Journal of The Electrochemical Society, 162(2015) B217-B24.

[24] J. Muñoz, J. Bartrolí, F. Céspedes, M. Baeza, Influence of raw carbon nanotubes diameter for the optimization of the load composition ratio in epoxy amperometric composite sensors, Journal of Materials Science, 50(2015) 652-61.

[25] J. Muñoz, J. Bastos-Arrieta, M. Muñoz, D. Muraviev, F. Céspedes, M. Baeza, CdS quantum dots as a scattering nanomaterial of carbon nanotubes in polymeric nanocomposite sensors for microelectrode array behavior, Journal of materials science, 51(2016) 1610-9.

[26] S. Güney, O. Güney, A novel electrochemical sensor for selective determination of uranyl ion based on imprinted polymer sol-gel modified carbon paste electrode, Sensors and Actuators B: Chemical, 231(2016) 45-53.

[27] J. Muñoz, A. González-Campo, M. Riba-Moliner, M. Baeza, M. Mas-Torrent, Chiral magnetic-nanobiofluids for rapid electrochemical screening of enantiomers at a magneto nanocomposite graphene-paste electrode, Biosensors and Bioelectronics, (2018).

[28] P. Fabry, J. Fouletier, Chemical and Biological Microsensors: Applications in Fluid Media: John Wiley \& Sons; 2013.

[29] E. Tsivion, S.P. Veccham, M. Head-Gordon, High-Temperature Hydrogen Storage of Multiple Molecules: Theoretical Insights from Metalated Catechols, ChemPhysChem, 18(2017) 184-8.

[30] H. Gulley-Stahl, P.A. Hogan, W.L. Schmidt, S.J. Wall, A. Buhrlage, H.A. Bullen, Surface complexation of catechol to metal oxides: an ATR-FTIR, adsorption, and dissolution study, Environmental science \& technology, 44(2010) 4116-21.

[31] L. Tchertanov, J.-F. Mouscadet, Target recognition by catechols and $\beta$-ketoenols: potential contribution of hydrogen bonding and $\mathrm{Mn} / \mathrm{Mg}$ chelation to HIV-1 integrase inhibition, Journal of medicinal chemistry, 50(2007) 1133-45.

[32] C.M. Van Den Berg, Z.Q. Huang, Determination of uranium (VI) in sea water by cathodic stripping voltammetry of complexes with catechol, Analytica Chimica Acta, 164(1984) 209-22.

[33] K. Oshita, A. Sabarudin, T. Takayanagi, M. Oshima, S. Motomizu, Adsorption behavior of uranium(VI) and other ionic species on cross-linked chitosan resins modified with chelating moieties, Talanta, 79(2009) 1031-5.

[34] J. Sedó, J. Saiz-Poseu, F. Busqué, D. Ruiz-Molina, Catechol-Based Biomimetic Functional Materials, Advanced Materials, 25(2013) 653-701.

[35] Q. Xue, Z. Liu, Y. Guo, S. Guo, Cyclodextrin functionalized graphene-gold nanoparticle hybrids with strong supramolecular capability for electrochemical thrombin aptasensor, Biosensors and Bioelectronics, 68(2015) 429-36.

[36] H. Zhao, X. Ji, B. Wang, N. Wang, X. Li, R. Ni, et al., An ultra-sensitive acetylcholinesterase biosensor based on reduced graphene oxide-Au nanoparticles- $\beta$-cyclodextrin/Prussian blue-chitosan nanocomposites for organophosphorus pesticides detection, Biosensors and Bioelectronics, 65(2015) 23-30.

[37] J. Muñoz, M. Riba-Moliner, L.J. Brennan, Y.K. Gun'ko, F. Céspedes, A. González-Campo, et al., Amperometric thyroxine sensor using a nanocomposite based on graphene modified with gold nanoparticles carrying a thiolated $\beta$-cyclodextrin, Microchimica Acta, 183(2016) 1579-89.

[38] J. Muñoz, J. Bastos-Arrieta, M. Muñoz, D. Muraviev, F. Céspedes, M. Baeza, Simple green routes for the customized preparation of sensitive carbon nanotubes/epoxy nanocomposite electrodes with functional metal nanoparticles, RSC Advances, 4(2014) 44517-24.

[39] R.T. Tom, V. Suryanarayanan, P.G. Reddy, S. Baskaran, T. Pradeep, Ciprofloxacin-protected gold nanoparticles, Langmuir, 20(2004) 1909-14.

[40] P. Dombovári, P. Kádár, T. Kovács, J. Somlai, K. Radó, I. Varga, et al., Accumulation of uranium on austenitic stainless steel surfaces, Electrochimica acta, 52(2007) 2542-51.

[41] J. Muñoz, L.J. Brennan, F. Céspedes, Y.K. Gun'ko, M. Baeza, Characterization protocol to improve the electroanalytical response of graphene-polymer nanocomposite sensors, Composites Science and Technology, 125(2016) 71-9. 
[42] N. Casacuberta, M. Lehritani, J. Mantero, P. Masqué, J. Garcia-Orellana, R. Garcia-Tenorio, Determination of U and Th $\alpha$ emitters in NORM samples through extraction chromatography by using new and recycled UTEVA resins, Applied Radiation and Isotopes, 70(2012) 568-73.

[43] J. Muñoz, R. Montes, M. Baeza, Trends in electrochemical impedance spectroscopy involving nanocomposite transducers: Characterization, architecture surface and bio-sensing, TrAC Trends in Analytical Chemistry , 97(2017), 201-2015.

[44] M.A. Raj, S.A. John, Assembly of gold nanoparticles on graphene film via electroless deposition: spontaneous reduction of Au 3+ ions by graphene film, RSC Advances, 5(2015) 4964-71.

[45] H. Jaegfeldt, T. Kuwana, G. Johansson, Electrochemical stability of catechols with a pyrene side chain strongly adsorbed on graphite electrodes for catalytic oxidation of dihydronicotinamide adenine dinucleotide, Journal of the American Chemical Society, 105(1983) 1805-14.

[46] M.A. Abu-Dalo, N.A. Al-Rawashdeh, I.R. Al-Mheidat, N.S. Nassory, Preparation and evaluation of new uranyl imprinted polymer electrode sensor for uranyl ion based on uranyl-carboxybezotriazole complex in pvc matrix membrane, Sensors and Actuators B: Chemical, 227(2016) 336-45.

[47] S. Agrahari, S. Kumar, A. Srivastava, lon selective electrode for uranium based on composite multiwalled carbon nanotubebenzo-15-crown-5 in PVC matrix coated on graphite rod, Journal of analytical chemistry, 69(2014) 36-44.

[48] Z.F. Akl, Electrochemical Selective Determination of Uranyl lons Using PVC Membrane Sensor, Electroanalysis, 29(2017) 1459-68.

[49] H. Rashidi Nassab, A. Souri, A. Javadian, M.K. Amini, A novel mercury-free stripping voltammetric sensor for uranium based on electropolymerized N-phenylanthranilic acid film electrode, Sensors and Actuators B: Chemical, 215(2015) 360-7.

\section{Biographies}

Jose Muñoz He received his PhD in Chemistry from Autonomous University of Barcelona (UAB) in 2015, with his $\mathrm{PhD}$ focused on electrochemical (bio)sensing using different carbon-based hybrid-nanomaterials. Currently, he is working as a post-doctoral researcher in the Department of Molecular Nanoscience and Organic Materials at Materials Science Institute of Barcelona (ICMAB-CSIC). His interests are on the development of carbon-based platforms as electrochemical transducers and as alternative gate electrodes in Electrolyte-Gated Field-Effect Transistor technology, falling his research under the areas of electroanalytical chemistry, surface engineering, electronics, nanomaterials and nanotechnology. 
Mireia Baeza She received her BSc in Chemistry in 1995 and completed her $\mathrm{PhD}$ in Analytical Chemistry in 2004 at the Autonomous University of Barcelona. In 2010 she was appointed as Associate Professor at the same University. She is specially focused on the study of automated analytical systems for environmental and industrial monitoring. Her research interests include microsystems for chemical analysis based on 3D and inkjet-printed technologies, the electrochemical improvement of amperometric sensors and biosensors based on allotropic graphite forms and the development of automated analysers for bioreactors control.

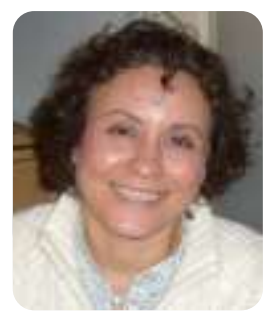

Raquel Montes She received her $\mathrm{PhD}$ in Chemistry focused on the characterization and optimization of amperometric sensors and biosensors based on carbon materials for analytical applications at Autonomous University of Barcelona in 2014. Currently, she is working as a researcher on the Department of Chemical, Biological and Environmental Engineering and Analytical Chemistry Department at Autonomous University of Barcelona. Her interests are focused on the electrochemical improvement of carbon-based (bio)sensors for sensing applications and their integration in automated analyzers for monitoring environmental parameters.

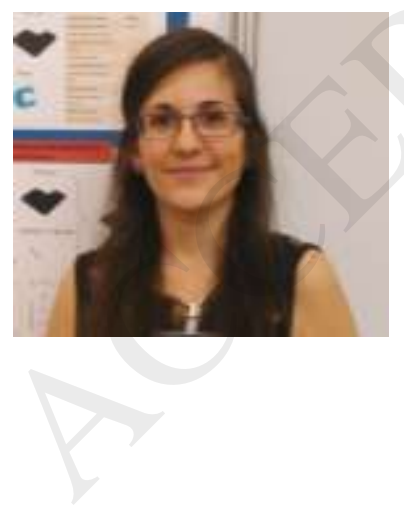

\section{Figure Captions}

Figure 1. TEM images of A) raw CNTs, B) Au-NP@CNTs, C) cat-1/Au-NP@CNTs and D) EDS spectrum of sample C. 
Figure 2. A) Nyquist diagram for the different nanocomposite-based electrodes containing $i$ ) bare electrode (CNTs/epoxy); ii) Au-NP@CNTs and iii) cat-1/Au-NP@CNTs. The impedance spectra were recorded in the frequency range $0.1 \mathrm{~Hz}$ to $100 \mathrm{kHz}$ in a $0.1 \mathrm{M}\left[\mathrm{Fe}(\mathrm{CN})_{6}\right]^{3-/ 4-}$ solution containing $0.1 \mathrm{M} \mathrm{KCl}$ as a benchmark redox marker. B) Cyclic voltammograms of (a) bare electrode (CNTs/epoxy) in absence of $\mathrm{UO}_{2}{ }^{2+}$ and (b) functionalized NC-CnPEs in absence of $\mathrm{UO}_{2}{ }^{2+}$ and presence of (c) $5 \mathrm{mg} \cdot \mathrm{L}^{-1}$ and (d) $10 \mathrm{mg} \cdot \mathrm{L}^{-1}$ of $\mathrm{UO}_{2}{ }^{2+}$ after 10 -minute incubation time under stirring conditions. Experimental conditions: $0.1 \mathrm{M}$ boric acid at $\mathrm{pH} 5.3$ (scan rate: $10 \mathrm{mV} \cdot \mathrm{s}^{-}$ $\left.{ }^{1}\right)$.

Figure 3. Calibration curve of current vs. $\left[\mathrm{UO}_{2}{ }^{2+}\right]$ at the cat-1/Au-NP@CNTs/epoxy nanocomposite sensor with its corresponding error bars $(n=9)$. Experimental conditions: $0.1 \mathrm{M}$ boric acid at pH 5.3 (working potential: $-0.4 \mathrm{~V} v s . \mathrm{Ag} / \mathrm{AgCl}$ ). Error bar was estimated as coefficient interval.

Figure 4. Different current signals collected from different analytes $\left(10 \mu \mathrm{g} \cdot \mathrm{L}^{-1}\right)$ for interfering study $(n=3)$. Inset: dashed line corresponding to the $5 \%$ of the uranyl ion signal, maximum allowed signal to analytically promulgate whether a compound acts as an interfering or not. Error bar was estimated as coefficient interval.

\section{Figure 1}



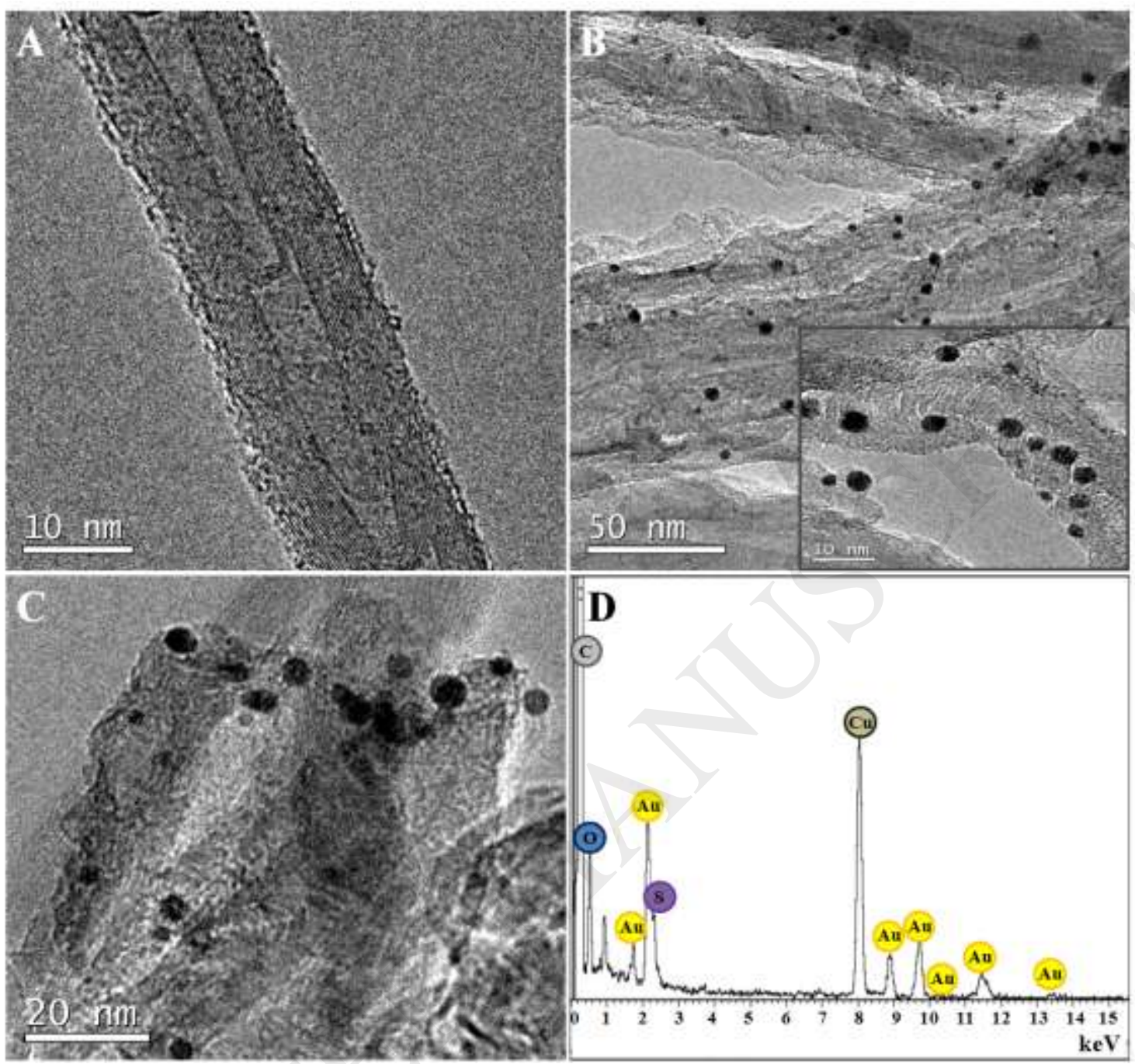

Figure 2 

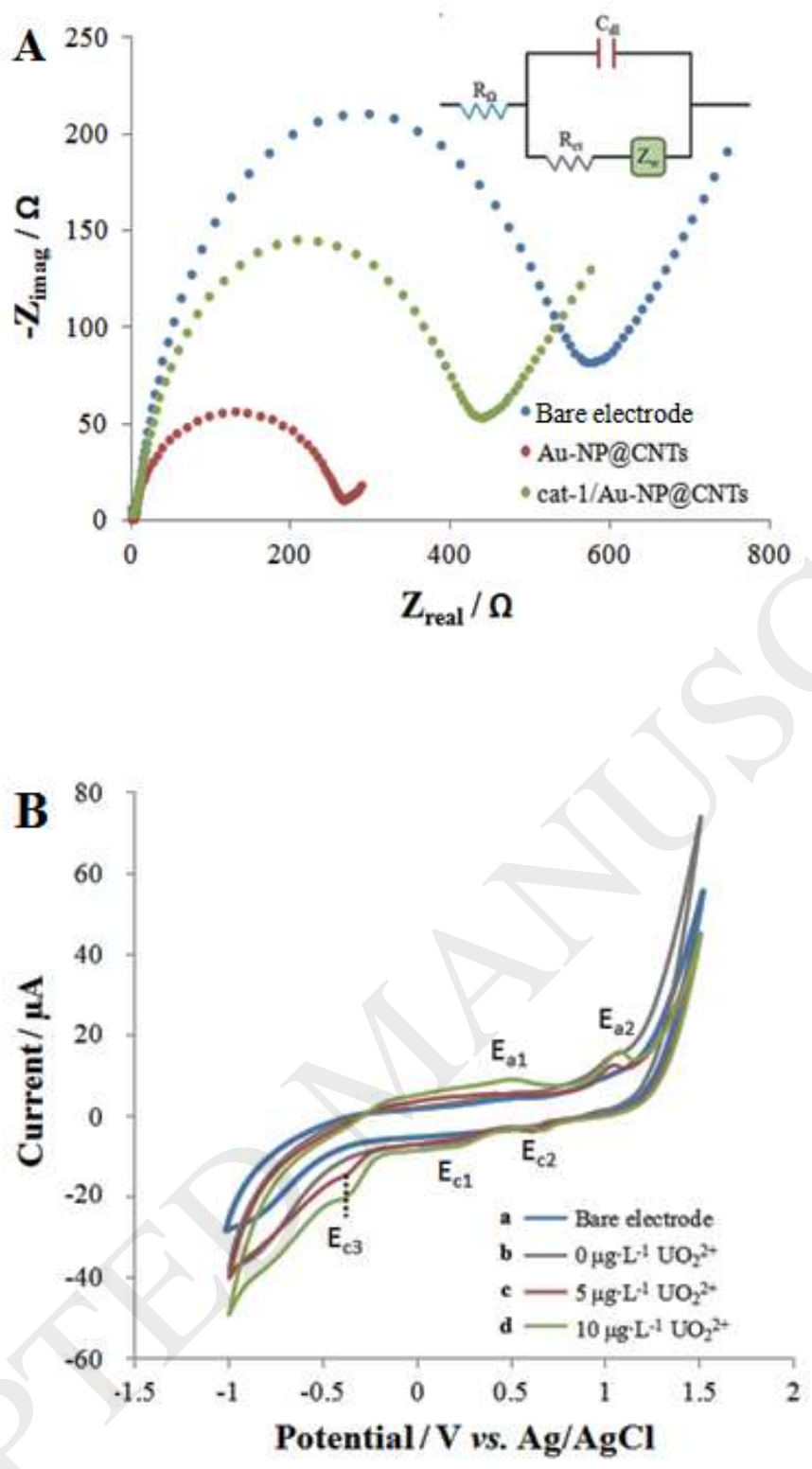

Figure 3 


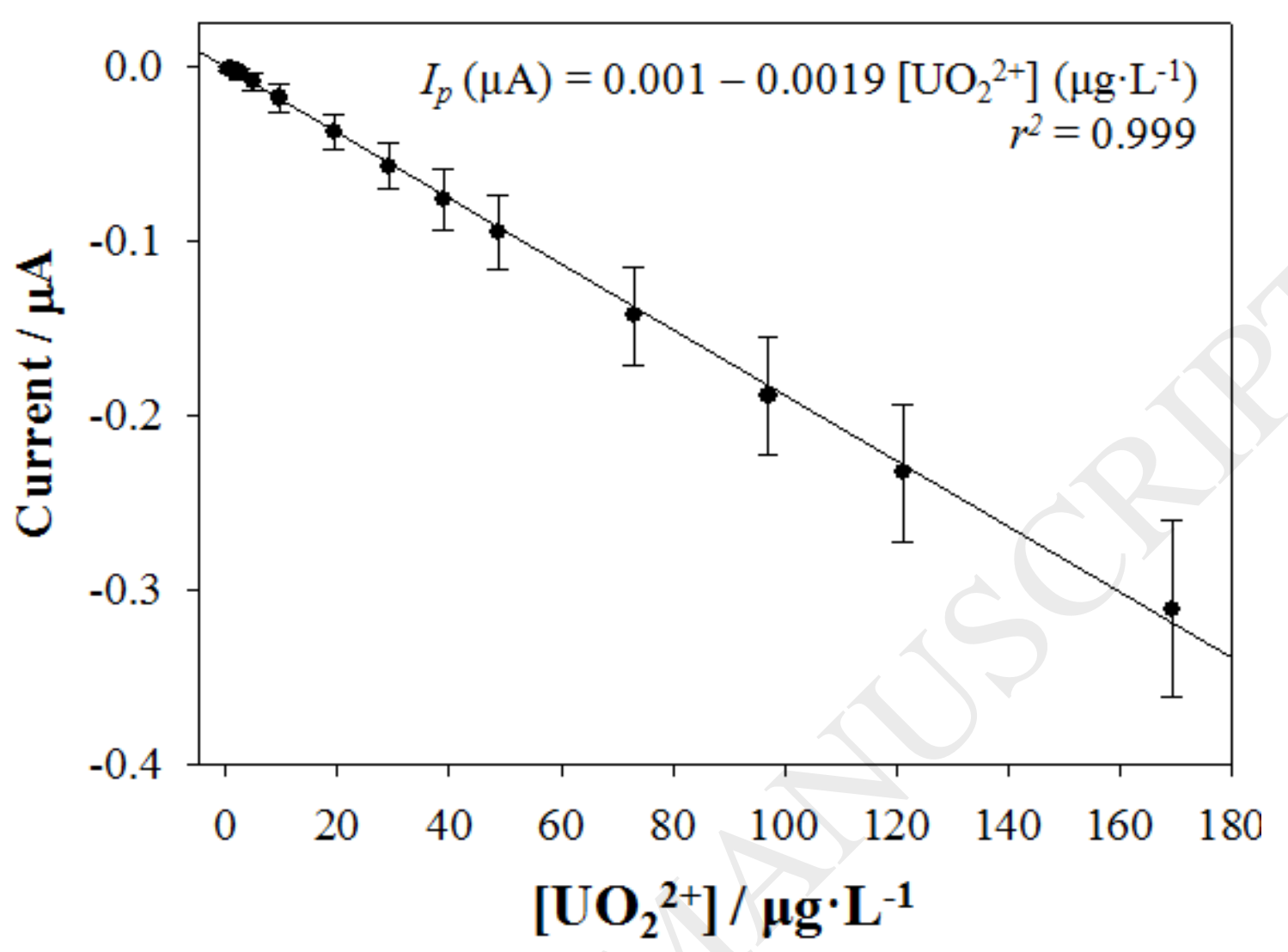

Figure 4 


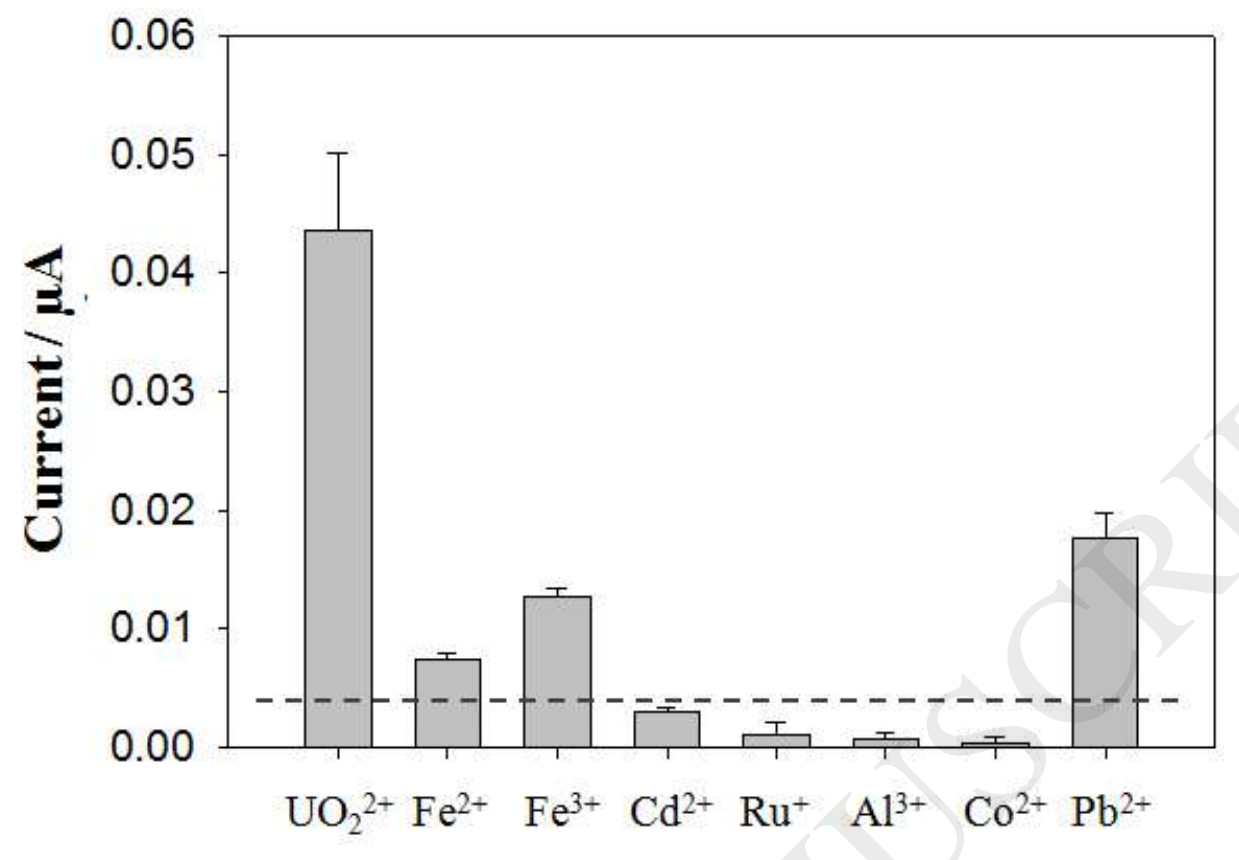

Scheme 1. Schematic representation (not in scale) for carrying CNTs with the thiolated catechol 1 (cat-1) for electrochemical recognition platform development towards the amperometric sensing of uranyl ion in water. 


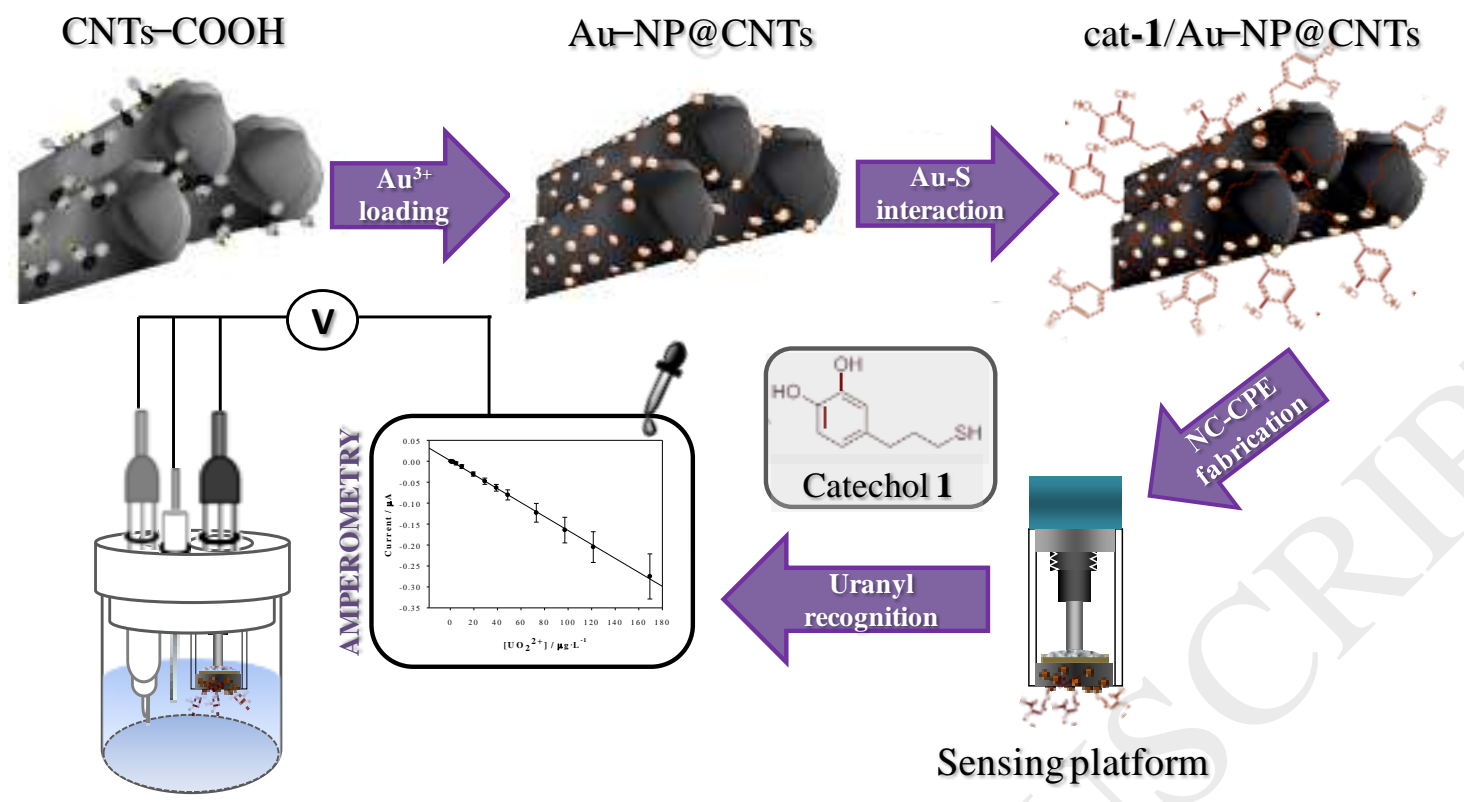

Electrochemical cell

Scheme 2. Synthesis of thiolated cat-1 used as for supramolecular recognition of $\mathrm{UO}_{2}{ }^{2+}$.<smiles>COc1cc(C/C=C\Cc2ccc(CCC[Se]C(C)(C)C(=O)O)c(OC)c2)ccc1O</smiles> 
Table 1. Comparative results from the $\mathrm{UO}_{2}{ }^{2+}$ determination in real environmental samples between the present electrochemical sensor and the common standard spectroscopic methods. Error was estimated as the standard deviation (SD), $n=3$.

\begin{tabular}{|c|c|c|c|c|c|}
\cline { 2 - 6 } \multicolumn{1}{c|}{} & \multicolumn{5}{|c|}{ Analytical method } \\
\hline Sample & $\begin{array}{c}\text { ICP-MS (1) } \\
\left(\boldsymbol{\mu g} \cdot \mathbf{L}^{-\mathbf{1}}\right)\end{array}$ & $\begin{array}{c}\text { ICP-MS (2) } \\
\left(\boldsymbol{\mu} \mathbf{g} \cdot \mathbf{L}^{-\mathbf{1}}\right)\end{array}$ & $\begin{array}{c}\boldsymbol{\alpha - S p e c t r o m e t r y} \\
\left(\boldsymbol{\mu g} \cdot \mathbf{L}^{-\mathbf{1}}\right)\end{array}$ & $\begin{array}{c}\text { Nanocomposite } \\
\mathbf{s e n s o r}(\mathbf{1}) \\
\left(\boldsymbol{\mu g} \cdot \mathbf{L}^{-\mathbf{1}}\right)\end{array}$ & $\begin{array}{c}\text { Nanocomposite } \\
\mathbf{s e n s o r}(\mathbf{2}) \\
\left(\boldsymbol{\mu g} \cdot \mathbf{L}^{-\mathbf{1}}\right)\end{array}$ \\
\hline S1 & $38 \pm 3$ & $41.0 \pm 0.1$ & $35 \pm 3$ & $37 \pm 1$ & $37 \pm 3$ \\
\hline S2 & $54 \pm 3$ & $86.0 \pm 0.2$ & $82 \pm 4$ & $55 \pm 2$ & $55 \pm 1$ \\
\hline S3 & $5 \pm 3$ & $5.6 \pm 0.1$ & $4.0 \pm 0.5$ & $8 \pm 2$ & $6 \pm 2$ \\
\hline S4 & $2.1 \pm 0.1$ & $4.6 \pm 0.1$ & $3.3 \pm 0.4$ & - & $4 \pm 2$ \\
\hline
\end{tabular}

